\title{
Lugar Aberto Para os Amigos: A Música Como Construção de Uma Identidade Cultural na Visão do Documentário
} L.A.P.A (2007) ${ }^{1}$

\section{Pâmela de Bortoli Machado}

Pâmela de Bortoli Machado - Bacharel em Música pela Universidade Federal de Santa Maria e Universidade Federal de Pelotas. Atualmente é mestranda na Universidade Estadual de Campinas na área de Multimeios, no qual pesquisa acerca da música como instrumento de inclusão social e digital a partir da representação de documentários brasileiros.

E-mail: pam.dbmac@gmail.com

${ }^{1}$ As imagens apresentadas no artigo foram retiradas do filme L.A.P.A., com autorização do diretor Cavi Borges.
${ }^{2}$ Glauber Rocha: o desejo da história in XAVIER, Ismail. O Cinema Brasileiro Moderno. São Paulo: Paz e Terra, 2001.
Resumo: Este artigo verifica a possibilidade da construção de uma identidade cultural pela música na representação de um documentário contemporâneo brasileiro. A partir das entrevistas e depoimentos expostos pelo documentário L.A.P.A (2007), estabelecem-se os paradigmas da música no que se refere a seu potencial enquanto fator de inclusão social. Além disso, com embasamento na proposta do documentário, evidencia-se a relação da música enquanto instrumento relevante perante a atividade cultural e etnografia do bairro da Lapa, localizada no Estado do Rio de Janeiro.

Palavras-Chave: documentário; música; identidade; cultural; etnografia.

Abstract: This article examines the possibility of building a cultural identity through music in contemporary documentary representation of a Brazilian. From the interviews and testimonies exposed the documentary LAPA (2007), establishes the paradigms of music in relation to its potential as a factor of social inclusion. Furthermore, with the proposed basis of the documentary, evidence of the relationship of music as an important instrument towards cultural activity and ethnography of Lapa, located in the State of Rio de Janeiro.

Keywords: documentary, music, identity, culture, ethnography.

O formato de documentário adotado pela geração de cineastas brasileiros a partir dos anos 1960 foi caracterizado por uma elevada ênfase na questão política e social. Os filmes pontuavam questões coletivas e, mesmo quando os personagens ou comunidades eram destacados, não se via multiplicidade de identidades, ou seja, os indivíduos representavam a síntese da experiência de grupos, classes e nações ${ }^{2}$.

Relacionada à década de 60 com o destaque no estudo de um grupo, frisa-se o surgimento da primeira inovação técnica, advindo como uma nova atividade para o observador-cineasta. France (2000) observa tal relevância ao mencionar a possibilidade de registrar longos planos contínuos (planos-sequências) compostos de imagens e de sons sincronizados:

O filme tornava-se, enfim, capaz de restituir o fluxo das atividades humanas, o continuum gestual, os tempos mortos de um processo etc. E o espectador de filmes etnográficos descobria, de repente, também essas dimensões essenciais do comportamento que são os múltiplos aspectos da vocalidade das pessoas filmadas. (...) As palavras, pronunciadas pelas pessoas filmadas no próprio 
decorrer do registro, substituíam o discurso, a voz que um comentarista, estranho ao grupo observado, impunha posteriormente às imagens mudas oferecendo na maioria das vezes fragmentos de gesticulação. (FRANCE, 2000: 341).

Partindo dessa ideia de representatividade de um grupo, o artigo visa, a partir de noções acerca do estudo de "sujeitos", exacerbar a potencialidade da música enquanto catalisador de uma identidade cultural dentro de um grupo, que Oliveira (2010) conceitua como:

(...) um sistema de representação das relações entre indivíduos e grupos, que envolve o compartilhamento de patrimônios comuns como a língua, a religião, as artes, o trabalho, os esportes, as festas, entre outros. É um processo dinâmico, de construção continuada, que se alimenta de várias fontes no tempo e no espaço. (OLIVEIRA, 2010: 1).

Assim, baseando-se na abordagem proposta pelo documentário L.A.P.A, procurase evidenciar como a música é colocada pelos músicos como construção de uma identidade cultural, além de sua relevância perante a etnografia do bairro da Lapa, no Estado do Rio de Janeiro, conforme citado em entrevista pelos diretores Cavi Borges e Emílio Domingos:

${ }^{3}$ Entrevista integrante da Série: Rio, Uma Cidade de Leitores. Programa n.36 - HIP HOP. 27 de maio de 2010.

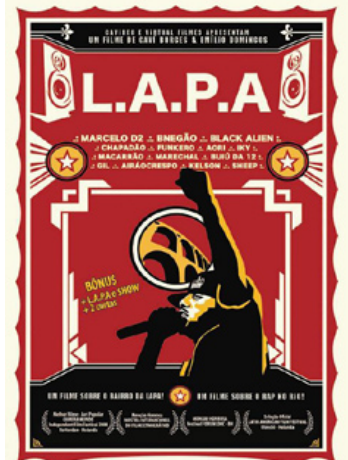

Figura 1: Cartaz do filme L.A.P.A
Bom, a ideia original era retratar os jovens que viviam do rap, que eram compositores e acompanhar um pouco ao longo de dois anos, como que era uma carreira de um artista que quer fazer hip-hop, rap. A Lapa acabou surgindo ao longo dessa filmagem. Ao longo do filme eles foram revelando a Lapa como essencial para contar aquela história ${ }^{3}$.

\section{Breve contextualização sobre os diretores de L.A.P.A e os personagens sociais}

\section{Emílio Domingos:}

Emílio Domingos é cineasta e cientista social formado pela UFRJ. Desde sua formação em 1997, trabalha com Documentário e Antropologia Visual. É diretor, pesquisador roteirista e assistente de direção em documentários, assim como pesquisador em alguns livros e CDs. Trabalhou também na curadoria da Mostra Internacional do Filme Etnográfico e em algumas exposições. É freelancer como pesquisador, assistente de direção e roteirista nas produtoras Conspiração Filmes e Video Filmes. Além de já ter trabalhado com os diretores Andrucha Waddington, Breno Silveira, João Moreira Salles, Lula Buarque de Hollanda, Paulo Caldas, Carolina Jabor, Denise Garcia e Marcus Vinícus Faustini, participou de filmes como Viva São João (2002), Pierre Verger: Mensageiro entre dois mundos (1998), Santa Cruz (2000), Filhos de Gandhy (2000), Amyr Klink: Mar Sem Fim (2001), Sons da Bahia (2002), Sou feia mas tô na Moda (2005), Velha Guarda da Portela (2009).

Além dessas realizações, foi pesquisador e assistente de curadoria na exposição Heranças do Samba, no Espaço Cultural dos Correios (em outubro de 2004) e Curador da X e XI Mostra Internacional do Filme Etnográfico (em 2005 e 2006), e participou como jurado da Mostra Competitiva do Festival Audiovisual Visões Periféricas (2007).

\section{Cavi Borges:}

Cavi Borges estudou cinema na Faculdade Estácio de Sá. É idealizador da locadora Cavídeo criada em 1997 e especializada em filmes de arte e referência para cinéfilos do Rio de Janeiro. Em 2000, dirigiu e produziu seu primeiro curtametragem em parceria com a cooperativa Fora do Eixo, o filme Sem Saída, e neste mesmo ano, em parceria com o Grupo Teatral Os Dezequilibrados, dirigiu 
${ }^{4}$ Dados fornecidos pelo site http:// www.academiabrasileiradecinema.com. br. Acesso em: 13 Jun. 2013.

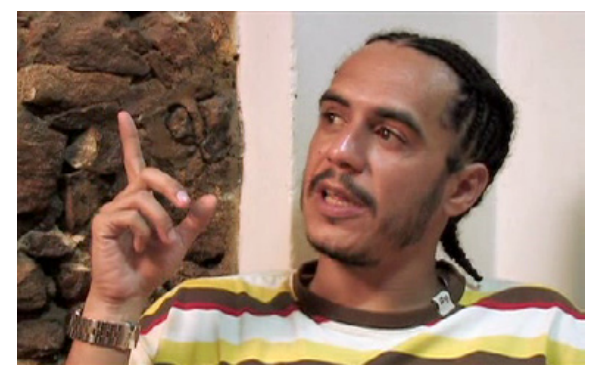

Figura 2: Marcelo D2, imagem do filme L.A.P.A.

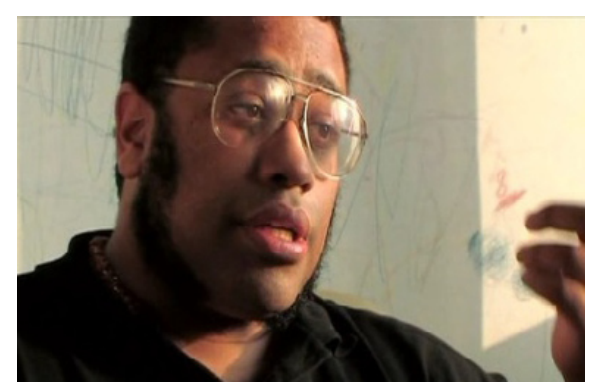

Figura 3: BNegão, imagem do filme L.A.P.A.

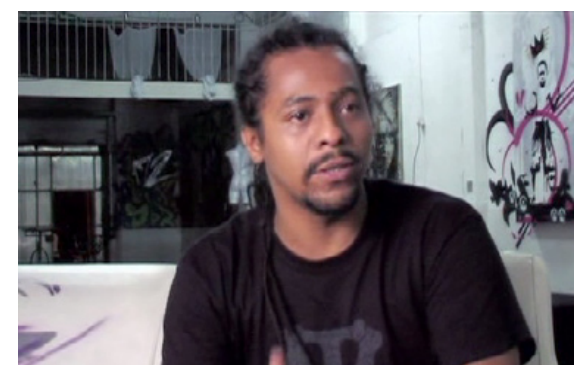

Figura 4: Black Alien, imagem do filme L.A.P.A. e produziu O Mundo de Andy. Em 2003, dirigiu e produziu Sou Rocinha Hip Hop, documentário de 22 minutos, e em 2005 iniciou uma parceria com o Grupo Nós do Morro, realizando diversos filmes como:

- 4 x Nós do Morro, de Cavi Borges e Gustavo Melo - filme exibido no Festival do Rio 2006;

- Neguinho e Kika de Luciano Vidigal, produzido por Cavi Borges - filme premiado no Festival Internacional de Marselha, França; melhor curta de ficção no Festival Internacional de curtas do Rio de Janeiro - Curta Cinema 2005 - como melhor filme de ficção; Festival de São Carlos como melhor curta de ficção;

- As Cotias do Campo do Santana, de Pedro Rossi, produzido por Cavi Borges;

- Picolé Pintinho e Pipa, ficção de 15 minutos, um filme de Gustavo Melo produzido por Cavi Borges. Premiado no Edital do Minc para curtas metragens de Temática Infantil que estreou na Sessão de Abertura do Festival Internacional de curtas do Rio de Janeiro - Curta Cinema 2006;

- Minha Área, Cavi Borges co-dirigiu e co-produziu este documentário de 22 minutos que estreou na Mostra do Filme Etnográfico, além de ter sido exibido no Festival Internacional de Curtas do Rio de Janeiro - Curta Cinema 2006 - e na Mostra de Cinema de Tiradentes 2007;

- Codirigiu e Coproduziu o curta-metragem 7 Minutos, que estreou no Festival Internacional de Curtas do Rio de Janeiro - Curta Cinema 2006 -, ganhando dez prêmios.

Além desses filmes, no início de 2008 finalizou seu novo projeto de curtametragem em $35 \mathrm{~mm}$ chamado Engano e dirigiu 20 episódios da série Mateus Balconista que faz parte do projeto TV Oi Móvel, primeiro canal de TV para celular do Brasil.

\section{Personagens ${ }^{4}$ :}

\section{Marcelo D2}

Marcelo, 39 anos. Nascido em São Cristóvão e criado em Maria da Graça e em Andaraí. Conhecido como um dos grandes nomes da música moderna brasileira, Marcelo teve sua origem musical na Lapa, conforme diz no filme: "ia à Lapa antes de ter MC, antes de eu mesmo ser MC." Relatou no documentário as dificuldades para produzir sua música no início de carreira, o que ocorre com muitos MCs até hoje. D2 não se esquece das suas origens e é visto com frequência nos eventos de rap no bairro. Com mais de 15 anos de carreira, desde o Planet Hemp, gravou junto com Marechal e Aori, no seu último CD Meu Samba é Assim uma música que dá nome ao filme: L.A.P.A, um hino de amor ao bairro.

\section{BNegão}

Bernardo, 32. Morador de Santa Teresa. Ex-rapper do Planet Hemp, em que rimava junto com D2 e Black Alien; já percorreu as principais capitais do país e da Europa. Lançou seu primeiro CD solo em 2003 e é um dos primeiros artistas brasileiros a disponibilizar um álbum para ser baixado via internet. Toda essa experiência o legitima a fazer uma das melhores análises sobre essa geração de músicos. No filme, ele aparece cantando no Largo da Lapa com os arcos ao fundo.

\section{Black Alien}

Gustavo, 33 anos, niteroiense, subiu num palco pela primeira vez em 1993. Também ex-integrante do Planet Hemp, lançou seu primeiro CD solo em 2004: Babylon by Gus Volume 1. Em 2003, sua música Quem Que Caguetou?/Follow Me fez enorme sucesso na Europa num comercial e foi remixada por um dos 


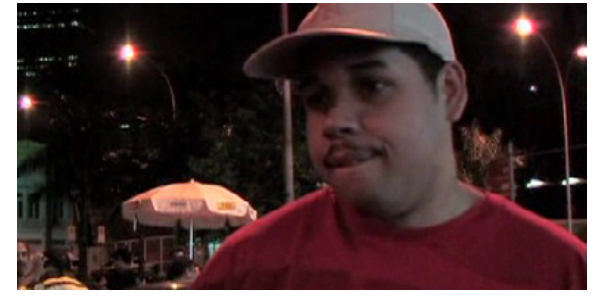

Figura 5: Chapadão, imagem do filme L.A.P.A.

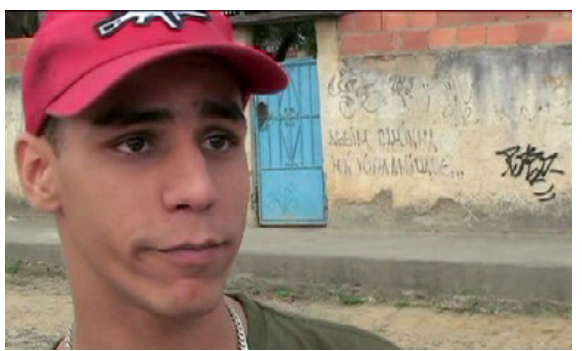

Figura 6: Funkero, imagem do filme L.A.P.A.

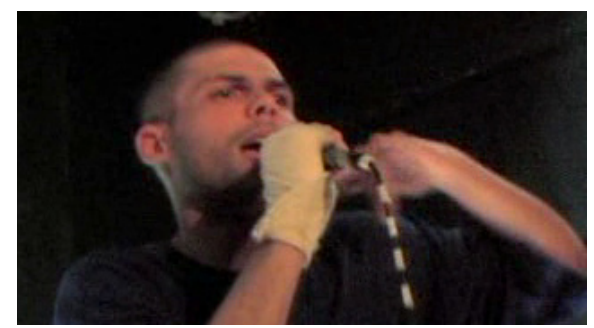

Figura 7: Marechal, imagem do filme L.A.P.A.

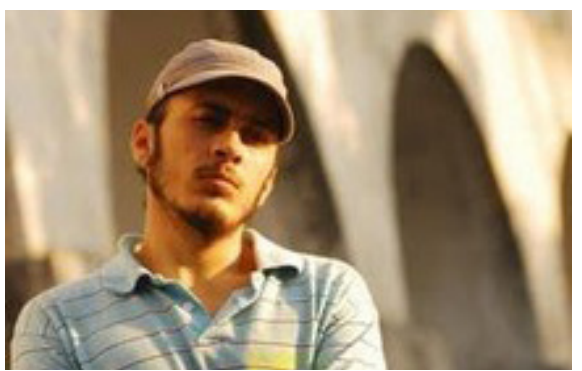

Figura 8: Iky, imagem do filme L.A.P.A.

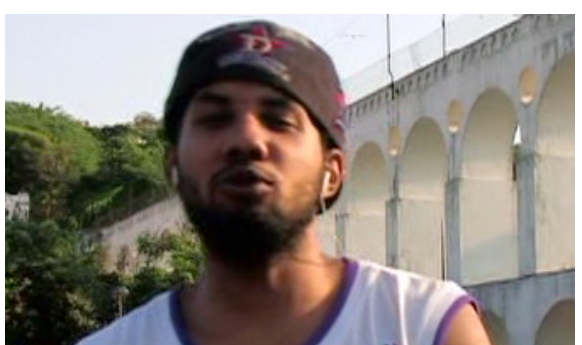

Figura 9: Aori, imagem do filme L.A.P.A.

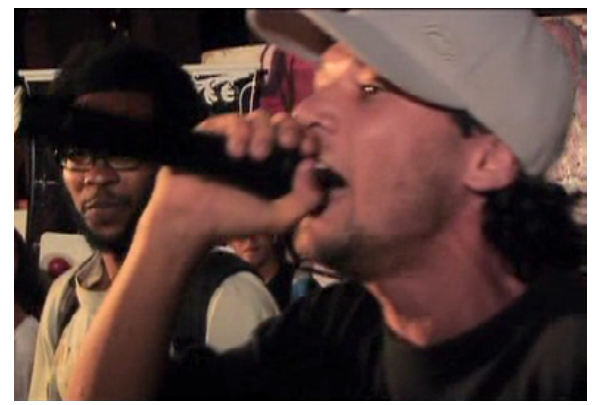

Figura 10: Gil, imagem do filme L.A.P.A. maiores DJs do mundo, Fatboy Slim, tornando-se um novo hit. Num dos melhores momentos do filme, fala sobre sua aversão à indústria da música e das contradições do rap brasileiro.

\section{Chapadão}

João Paulo, 26 anos. Mudou-se do Irajá para a Lapa. Ganhou o apelido quando teve que cantar após uma noite mal dormida. Trabalha como eletricista durante o dia, trocando lâmpadas e rimas com a mesma determinação. Desenvolve um estilo de rimar invertendo as sílabas das palavras, no qual segundo ele "a rima serve pra exercitar os neurônios".

\section{Funkero}

Vitor Hugo, 23 anos. Criado no Jardim Catarina, favela de São Gonçalo. A maior influência para escrever rap foi Monteiro Lobato e seu livro Reinações de Narizinho. Encantou-se ao ir à Lapa e, ao ver uma batalha de MCs, decidiu ser um também. Cresceu nos bailes os quais frequenta até hoje, mas agora cantando. Cronista do cotidiano, Funkero desenvolve a ponte entre o rap e o funk carioca, além de outros ritmos.

\section{Marechal}

Rodrigo, niteroiense de 25 anos, é um "veterano" com dez anos de carreira. Era o MC residente da lendária festa "Zoeira" na Lapa. No filme constata que o lugar de origem da festa virou uma igreja batista. É reconhecido como um dos maiores rimadores do país e mestre do improviso.

\section{Iky}

Luís Henrique - 26 anos. Produtor musical e também MC, é nascido em Volta Redonda e veio morar no Rio por causa da paixão pelo rap. Tem seu estúdio caseiro na Rua do Resende, coração da Lapa. Nas cercanias é onde Iky compra discos que servem de matéria-prima para o seu trabalho de colagem musical. 0 bairro alimenta sua criação e por meio do estúdio "Campo de Concentração", ele transforma a poesia de vários MCs em música.

\section{Aori}

Anwonrianaga, aos 27 anos é o que, de todos os MCs, melhor representa a "L.A.P.A.", uma vez que é nascido e criado no bairro. É integrante do duo INUMANOS junto com o DJ Babão. Começou a cantar em 1998 e é fundador da Tradicional Batalha do Real, um dos temas do documentário.

\section{Gil}

Gilmar, aos 22 anos, é uma das revelações da nova geração de MCs da Lapa, sendo responsável por duas batalhas antológicas no filme. Vindo de Jacarepaguá, de jeito malandro e tranquilo de garoto, caracteriza-se por sua velocidade de improviso e interação com o público.

\section{Um olhar sobre o outro: a criação de uma identidade cultural pelo rap}

L.A.P.A vem com a ideia de explorar o universo do hip-hop carioca. Mesmo assim, não é apenas um filme sobre essa cena musical, uma vez que sua jornada vai além das rimas dos MCs e traz para aos espectadores o cotidiano de quem busca sobreviver no Brasil através da música. Assim, por meio de cenas da região da Lapa (figuras 11 e 12) e entrevistas de MCs como Marcelo D2, BNegão, Black Alien, Chapadão, Funkero, Marechal, Iky, Aori e Gil, o documentário parte para a 


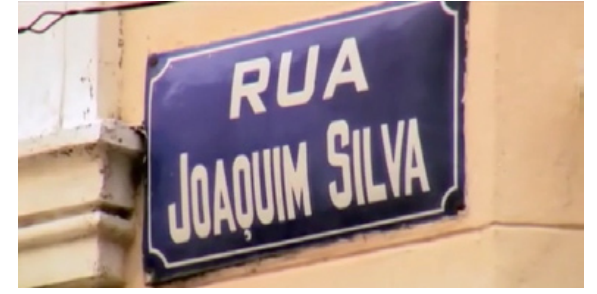

Figura 11: A rua Joaquim Silva fica na subida dos arcos da Lapa, conhecida como uma das ruas mais tradicionais da boemia carioca.

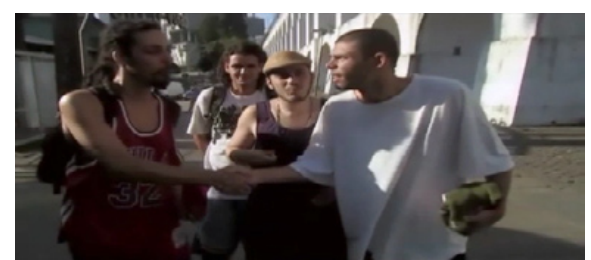

Figura 11: A rua Joaquim Silva fica na subida dos arcos da Lapa, conhecida como uma das ruas mais tradicionais da boemia carioca.

${ }^{5}$ Entrevista integrante da Série: Rio, Uma Cidade de Leitores. Programa n.36. HIP HOP. 27 maio de 2010.

\footnotetext{
${ }^{6}$ A história do hip-hop é abordada em minúcias no artigo $O$ nego drama do rap: entre a lei do cão e a lei da selva, de Bruno Zeni (2004), disponível em: $<$ http://www.scielo.br/pdf/ea/v18n50/ a20v1850.pdf>.
}

abordagem de como o rap tornou-se ponto de referência para o chamado Lugar Aberto Para os Amigos, pontuado como bairro da Lapa.

Além disso, os diretores frisam a ideia de que não buscaram apenas fazer o filme sobre o estilo musical do rap e hip-hop, mas também mostrar as implicações de quem decide viver de música de forma independente, dentro do contexto do bairro da Lapa:

Tinha um fato de a gente fazer um filme que é um filme bem específico sobre hip-hop e não queríamos que o filme atingisse só as pessoas que gostassem de hip-hop. Então achamos que se a gente humanizasse os personagens, mostrássemos o cotidiano, o dia a dia, a família dele, na casa dele, isso passaria a interessar todo mundo, um interesse universal sobre a pessoa não só sobre o ritmo ou estilo que ele canta ou que ele gosta. Quando vamos para a casa do Chapadão, no qual mostra a mãe dele falando, você atinge todos os públicos não só as pessoas que gostam de rap (...) Apesar de o filme permear a cultura hip-hop, ele está falando de coisas que vão além. A mãe do Chapadão é uma figura essencial no filme porque, de certa maneira, ela impulsiona o Chapadão a seguir o sonho dele, que é ser um artista de rap ${ }^{5}$.

Enfatizando tal menção, Oliveira (2009) acrescenta que mesmo o documentário passando a "dar voz" aos músicos, ele o faz com personagens sociais que de fato já tenham a sua própria, mais ou menos articulada, e requeiram este espaço com propriedade. L.A.P.A. sabe como tirar exatamente isso que quer de seus protagonistas, e ao longo do processo, ainda forçar uma complementaridade totalizante entre as figuras, cuja soma seria igual ao "rap carioca". E, relacionado aos personagens sociais, salientam-se suas peculiaridades quanto à maneira de defender seus próprios estilos de composição:

De Funkero ouviremos sempre as melhores frases, os melhores casos, as melhores rimas. É quem já se posicionou de maneira segura o bastante em relação a sua arte a ponto de perceber suas ranhuras e seus prazeres sem que uma coisa e outra condicionem exclusivamente o trabalho: é quem diz que o que o salvou não foi o rap, mas os livros (é um leitor de Monteiro Lobato), quem atua com um verdadeiro projeto artístico sobre a aproximação do rap com o funk (para o qual recebe um ótimo plano de improviso com um beatboxer nas ruas sem asfalto do Jardim Catarina). Já Chapadão é muito menos programático na construção de sua carreira e de sua figura, dele o filme recebe uma inocência e "um atrapalho" quase cômicos. Contra a imagem do sujeito que sobreviveu a perdas que nunca saberemos exatamente quais foram, surge este outro inserido dentro de um ambiente familiar suburbano tradicionalíssimo, uma reunião no sofá de casa, onde Chapadão recebe sermões do pai, safanões e afagos da mãe, que diz lutar contra a discriminação sofrida pelo filho quando anuncia aos outros que o rap é sua profissão (OLIVEIRA, 2009: 1)

No filme dos diretores Emílio Domingos e Cavi Borges, as experiências de vida dos MCs são ilustradas de maneiras distintas e mesmo com letras focadas em audiências diferentes e com conflitos específicos, o discurso ideológico mais estável deste tipo de música no contexto brasileiro expressa-se na integração dos gêneros de rap e o chamado hip-hop .

Este movimento cultural, que pode ser hoje situado na esfera dos níveis superiores da ideologia do cotidiano, consolida-se em um momento histórico determinado, e para vislumbrá-lo é necessário que se faça uma análise diacrônica do surgimento deste tipo de cultura urbana periférica no Brasil.

No final dos anos 1980, a violência urbana começa a tomar contornos mais bem definidos em grandes centros, e as adversidades que eram restritas a favelas e a comunidades afastadas passaram a se instalar nos espaços centrais de 
metrópoles brasileiras. Jovens negros ou pardos e moradores de favela passaram a ter visibilidade sendo associados à violência e à criminalidade, tornando-se os vilões identificáveis de um Brasil antes tido no imaginário urbano como pacífico e festivo.

Este procedimento se efetiva, visto que o desconhecido, mesmo estando próximo, gera uma insegurança. O modo mais rápido para eliminar este sentimento é "exterminar" o desconhecido que outrora era visto como exótico. Para o antropólogo Hermano Viana (2005 apud SOUZA, 2006), "o grau de 'exotismo' de um fenômeno social é uma função quase direta da possibilidade de vê-lo transformado em estereótipo por grupos para os quais esse fenômeno é considerado exótico" (p.6). Com o processo de ver além do exótico, tem-se uma maneira fácil de explicar uma situação que é extremamente mais complexa, identificando ainda alguns culpados. Lançando um estigma sobre estes sujeitos a serem demonizados, tem-se a segurança de saber quem são os agentes da violência urbana, instaurando o medo e a desconfiança perante um inimigo agora identificável.

Nos jogos de conflito entre as estruturas ideológicas, temos a expressão dos níveis superiores da ideologia do cotidiano estruturados a partir do hip-hop e do funk, que emergidos de favelas e locais periféricos, extrapolaram estes limites, expressando-se como movimentos culturais antagônicos àquilo que se teria como oficialmente legitimado e propagado. Esses dois movimentos, "ao longo dos últimos 20 anos, tornaram-se porta-vozes de uma camada de excluídos que nesse mesmo período apenas cresceu. Eles revelam um Brasil fragmentado e disperso" (SOUZA, 2006, p.5).

As representações musicais de ambos concedem visibilidade a conflitos e tensões que de outra forma seriam pouco aparentes. Logo, para Souza (2006), identidades criadas a partir das músicas ajudam na compreensão da conjuntura sociocultural das cidades onde estas expressões são formuladas:

Em especial, focando no movimento hip-hop, sua consolidação no seio de regiões periféricas de centros urbanos faz com que ele se torne um agente catalisador de novas experiências sociais e culturais para os jovens de periferia. Se, de um lado, o traficante serve de espelho para esse mesmo jovem, por outro, os líderes de movimentos como o hip-hop são referências nas comunidades onde atuam (SOUZA, 2006:8).

Contextualizados sob o bairro da Lapa, os MCs utilizam o rap como manifestação de uma vivência demarcada por problemas sociais como a desigualdade e empregabilidade. Segundo Marcelo, 39 anos, conhecido como Marcelo D2, as dificuldades para produzir sua música no início de carreira são as mesmas que muitos MCs passam até hoje, como a falta de espaço na grande mídia e divulgação do trabalho enquanto músico independente. Já Bernardo, 32 anos, sob o apelido de BNegão é apresentado como um dos primeiros artistas brasileiros a liberar um álbum para ser baixado via internet, enfatizando sua experiência acerca das novas tecnologias inseridas no mercado da música.

Assim, a representação passa a ocorrer por depoimentos que possibilitam a compreensão do meio que se inserem, já colocada por Miotello (2005) como mais bem expressa por palavras, uma vez que "não precisa de outro meio para ser produzida a não ser o próprio ser humano em presença de outro ser humano" (MIOTELLO, 2005: 170). E, com base na potencialidade da expressão e a partir dos relatos de suas experiências e letras de músicas, a interação entre a música e a realidade social vivida no ambiente da favela é pontuada. A desigual distribuição de renda é exclamada e protestada sob forma de letras que utilizam o rap como expressão de seus discursos ideológicos. Para Souza (2006), mais do que uma 
expressão sonora e ideológica, o rap potencializa o diálogo e modifica seu próprio conteúdo legitimado no cotidiano na medida em que as várias facetas do gênero musical representam em sua maior parte conflitos que são internos aos espaços da periferia:

Essa estratégia materializa o desejo de ser ouvido, de ser visto. Construir um discurso com tais características sanciona a concretude de uma "narrativização" em que a malha dos excluídos ganha direito de voz, de narrar a sua história e de assim marcar a sua presença perante a sociedade, mesmo que o alcance não seja por completo (SOUZA, 2006: 9).

Baseando-se na premissa de que o rap é instrumento de comunicação, inclusão e contextualização de um grupo, estabelecem-se tais diretrizes com o documentário e a forma como se dá a ideia de inclusão pela música a partir da visão de um vídeo documentário brasileiro.

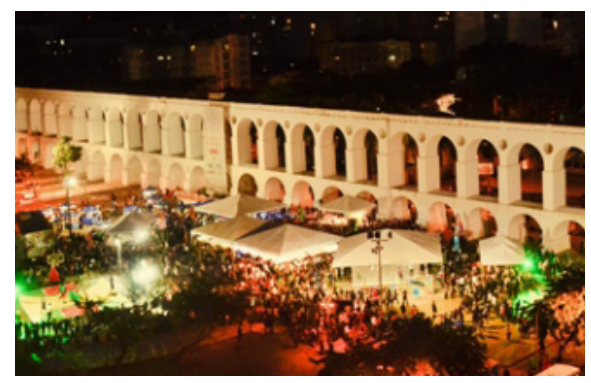

Figura 13: Cena do filme L.A.P.A

\section{Lapa: etnografia e instrumento na construção de uma identidade cultural}

A Lapa ficou famosa nas décadas de 1920 e 1930 por seus cabarés, clubes de jogo, restaurantes, botequins e hospedarias, tanto que, com o passar do tempo, deixou de ser um lugar de moradia para se tornar um espaço exclusivamente boêmio. Tradicional reduto da malandragem carioca, a região começou a declinar em 1940, devido à repressão do Estado Novo às atividades ilícitas e à concorrência com a agitada vida noturna de Copacabana.

Entretanto, a Lapa nunca deixou de ter seu público cativo, e no início da década de 1950, apesar do processo de decadência que vinha sofrendo, a Lapa já era um dos principais pontos de referência da vida noturna da cidade. "Enquanto a cidade dorme, a Lapa fica acordada, acalentando quem vive de madrugada." Assim é conhecido o trecho da música "A Lapa", composta por Herivelto Martins e Benedito Lacerda, em 1949, e interpretada por Francisco Alves, fazendo referência à Lapa naquela época, marcada pelo samba e pela malandragem. $O$ bairro fez história ao acolher e inspirar renomados artistas da música popular brasileira. $\mathrm{O}$ local, com seus famosos cabarés e restaurantes, é historicamente marcado como reduto da boemia carioca, uma verdadeira referência na cidade, frequentada pela fina flor dos artistas, intelectuais, e políticos.

Segundo Herschmann (2007), a história e as representações do bairro da Lapa e de seus arredores estão associadas à vida boêmia e musical da cidade e mesmo do país. Não é sem razão que vários escritores, intelectuais e músicos fazem referência ao bairro como uma espécie de "Montmartre carioca" ou "Nova Orleans tupiniquim", bem como enfatiza Maurício Carrilho (músico e proprietário da Acari Records, gravadora especializada em samba e choro), em entrevista a Herschmann (2007):

Contam-se nos dedos as cidades no mundo que podem ser reconhecidas pela música. São pouquíssimas. Você pode pensar em Sevilha na música flamenca, em Nova Orleans no som do Jazz, em Buenos Aires no tango e o Rio você liga imediatamente ao samba e ao choro. No poder público há inúmeras pessoas totalmente despreparadas, porque não conhecem a história da Lapa e da cidade, não sabem dar valor a esse patrimônio que a gente tem no Rio até hoje. E que faz da música do Rio e do Brasil, mas principalmente do Rio, um dos produtos de exportação melhor recebidos lá fora (CARRILHO apud HERSCHMANN, 2007: 36).

Ao longo do século XX, o bairro passou por vários ciclos em que a vida boêmia foi combatida ou incentivada, mas sempre manteve em alguma medida uma ligação com o universo da música. Segundo Lustosa (2001), constantemente 
encontramos representações que associam a boemia carioca à Lapa, região que aparece em diferentes momentos ligada à música e à vida noturna da cidade. O bairro parece ter passado por vários ciclos em que encontramos um enorme conjunto de narrativas que ora falam de uma vida cultural intensa, ora de um ambiente de decadência. Tal menção é enfatizada por Hermínio Belo (historiador, produtor e crítico de música popular) em entrevista a Herschmann (2007):

\begin{abstract}
A Lapa teve diversos momentos de ressurgimento, seguidos de períodos de crise. O bairro prova que existe um público para a boa música (...). Essa é, sem dúvida, uma característica da vida musical daquele bairro: a qualidade dos grupos que nele atuam. Evidentemente, sempre existem empresários oportunistas que objetivam apenas o lucro pecuniário, e a proliferação de casas acaba por prejudicar a qualidade do movimento. Mas acho que os estados brasileiros em geral têm a sua Lapa. Cada um deles tem sua Lapa particular. E nos faltam elementos para ter uma visão geral do problema do desenvolvimento da nossa música no Brasil. (BELO apud HERSCHMANN, 2007: 37-8).
\end{abstract}

O status da Lapa como território - "cidade da música" - também foi construído socialmente e naturalizado no imaginário social a partir de vários discursos (THOMPSON, 1992) - tais como o de músicos, de historiadores, de autoridade e de promotores do turismo - que circulavam na sociedade e eram veiculados constantemente na mídia. Quase todos invariavelmente "(re)inventavam" a mesma tradição, exaltando o passado e/ou a necessidade de preservação da memória do lugar como parte da "história oficial nacional". E, também destacado por Aori no documentário L.A.P.A, esta mesma ideia de troca cultural nacional predominante no século XX é ainda característica dos dias de hoje, antes somente vinculado pelo samba e choro, agora com a abertura para o rap:

\begin{abstract}
A Lapa no começo do século era o lugar onde se reuniram os sambistas pra mostrar o samba um pro outro e trocar uma ideia. E é mais ou menos o que rola ainda hoje, todo mundo se reúne aqui formalmente na sexta, no sábado à noite pra ir na batalha e para na rua, canta, galera ouve, vê quem é bom e quem não é, faz as parcerias. $\mathrm{O}$ bairro é transitório .
\end{abstract}

Entrevista de Aori extraída do
documentário L.A.P.A. 2007. 73min.

\footnotetext{
${ }^{8}$ Entrevista integrante da Série: Rio, Uma Cidade de Leitores. Programa n.36 - HIP HOP. 27 de maio de 2010.
}

Se, por um lado, $70 \%$ da música que é tocada ali até 2005 estava relacionada a estes dois gêneros musicais, fato que é um indicativo do interesse dos atores e empresários locais em dar certo "perfil" ao território, por outro lado, é preciso reconhecer que não há um impedimento explícito em se tocarem outros estilos musicais, como o rap. Como nos recorda Marcelo D2 em uma de suas músicas, a Lapa é de todas as "tribos", palco da boemia carioca. (HERSCHMANN, 2007: 50).

Vinculado ao documentário, os diretores também enfatizam a importância do bairro para que o movimento hip-hop tivesse espaço entre os MCs que estavam começando carreira no final da década de 1990. Assim, mencionam que "a Lapa tem essa característica de juntar todos os tipos de pessoas de classes sociais e o hip-hop no Rio se aproveitou disso e desenvolveu muito aqui (RJ) por isso também ${ }^{8 \prime \prime}$. 


\section{Os Lugares da Lapa: da música "de raiz" para as "Batalhas" e "Zoeira organizada"}

Uma visita pelas principais casas de espetáculo do bairro, como por exemplo, Asa Branca, Circo Voador, Teatro Rival, Fundição Progresso e Estrela da Lapa revelará que a Lapa é território de vários grupos sociais: roqueiros, forrozeiros, $b$-boys (do hip-hop), os apreciadores da MPB e da música pop.

Quando tratado da questão da identidade, os frequentadores da Lapa constroem e externalizam através do consumo um estilo de vida que os identifica como sendo pessoas "refinadas" e "conscientes", que segundo Bourdieu (2001), está relacionado com "bom gosto musical" e que valoriza a "cultura nacional", já que consomem gêneros musicais "de raiz", canônicos, extremamente valorizados pela crítica tradicional e considerados como "autênticos" pela maioria do público.

No documentário L.A.P.A, os músicos também destacam a relevância do bairro da Lapa no sentido de ser ponto de encontro para que soubessem da cena musical do rap que se destacou no final da década de 1990, conforme destaca Mr.Boca e Buiú da 12 em entrevista:

${ }^{9}$ Entrevista de Mr. Boca e Buiú da 12 extraída do documentário L.A.P.A. 2007. $73 \mathrm{~min}$.

\footnotetext{
${ }^{10}$ Entrevista integrante da Série: Rio, Uma Cidade de Leitores. Programa n.36 - HIP HOP. 27 de maio de 2010.
}

\begin{abstract}
A Lapa é um ponto de referência "do caramba", mas foi um ponto que veio depois de 95, 96 (...) A Lapa surgiu para agregar. Cada cantinho tipo um pessoal fazendo rap, e o pessoal achava que era absoluto, soberano. Eu achava. Todo mundo se convergiu pra Lapa, e aí foi a conversão. Todo mundo se encontrou na Lapa e descobriu que tinha uma cena naquele momento. Isso graças à Lapa ${ }^{9}$.
\end{abstract}

Como exemplo de espaço encontrado pelo rap na Lapa, destaca-se a Fundição Progresso como um dos principais locais que cede para a realização de eventos relacionados ao estilo musical. Atualmente, é uma das responsáveis pela organização de eventos como "Rap na Lapa", que abre espaço para a apresentação de MCs como MV Bill e Marcelo D2, além da realização de batalhas entre os MCs, destacado pelo documentário L.A.P.A (conforme ilustra a figura 14), bem como a referência dos diretores em entrevista remetendo a este evento:

A batalha do real cresceu tanto que eles criaram a Liga dos MCs, que é um concurso nacional de MCs. É uma batalha que acontece no Brasil inteiro. Eles selecionam pessoas de Recife, Minas Gerais, São Paulo, do Sul. Aí fazem a final no Rio, na Lapa ${ }^{10}$.

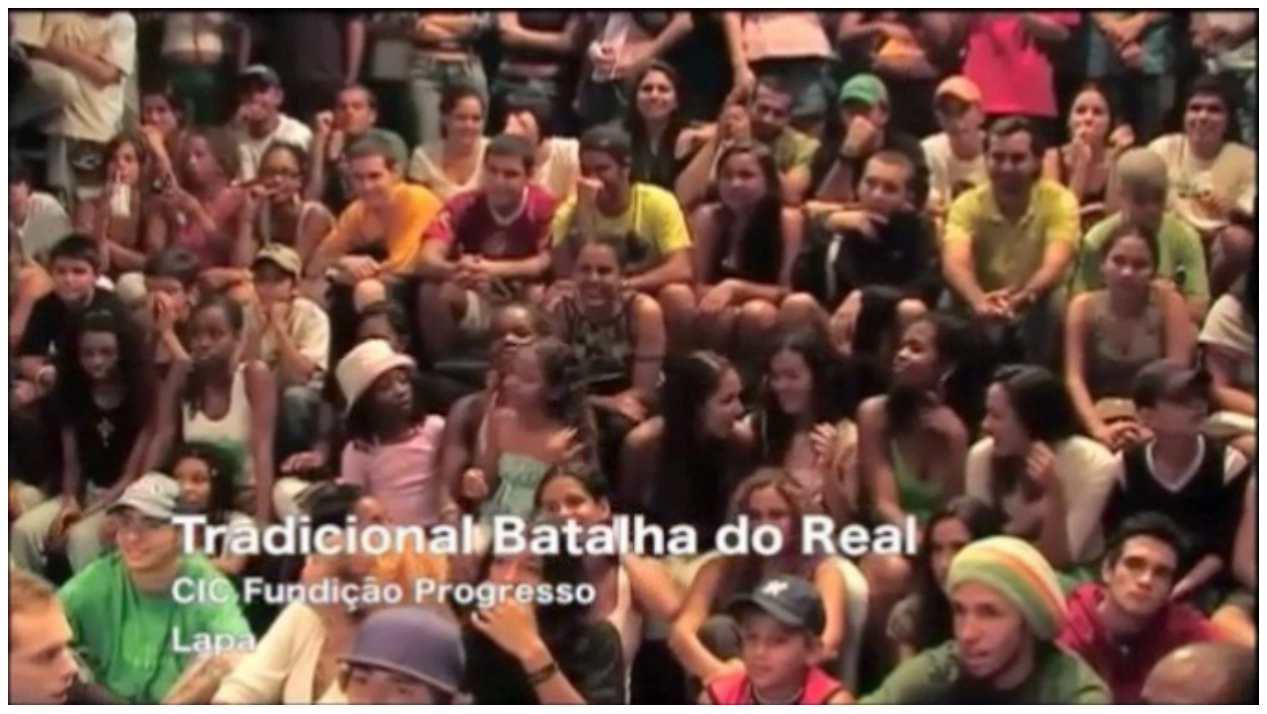

Figura 14: A chamada Tradicional Batalha do Real embora sendo um exemplo de integração social e cultural entre os jovens e músicos compositores, não é considerada como uma festa e sim um projeto de qualificação da cena musical do rap e hip-hop. 
${ }^{11}$ Entrevista de Marechal extraída do documentário L.A.P.A.2007.73min.
Além da Batalha do Real, outro evento que se tornou referente na contribuição para a criação de identidade de um grupo que compunha rap foi a chamada Zoeira, destacado pelo documentário L.A.P.A, conforme ilustra a figura abaixo e pela menção de Marechal:

Eu acho que todo mundo se conheceu mesmo na Zoeira (...). Aí por acaso na sinuca o cara fala que faz rap e todo mundo falava a mesma coisa, mas era esse o clima. O cara que não conhecia passava a conhecer e vice-versa, todo mundo trocava informação ${ }^{11}$.

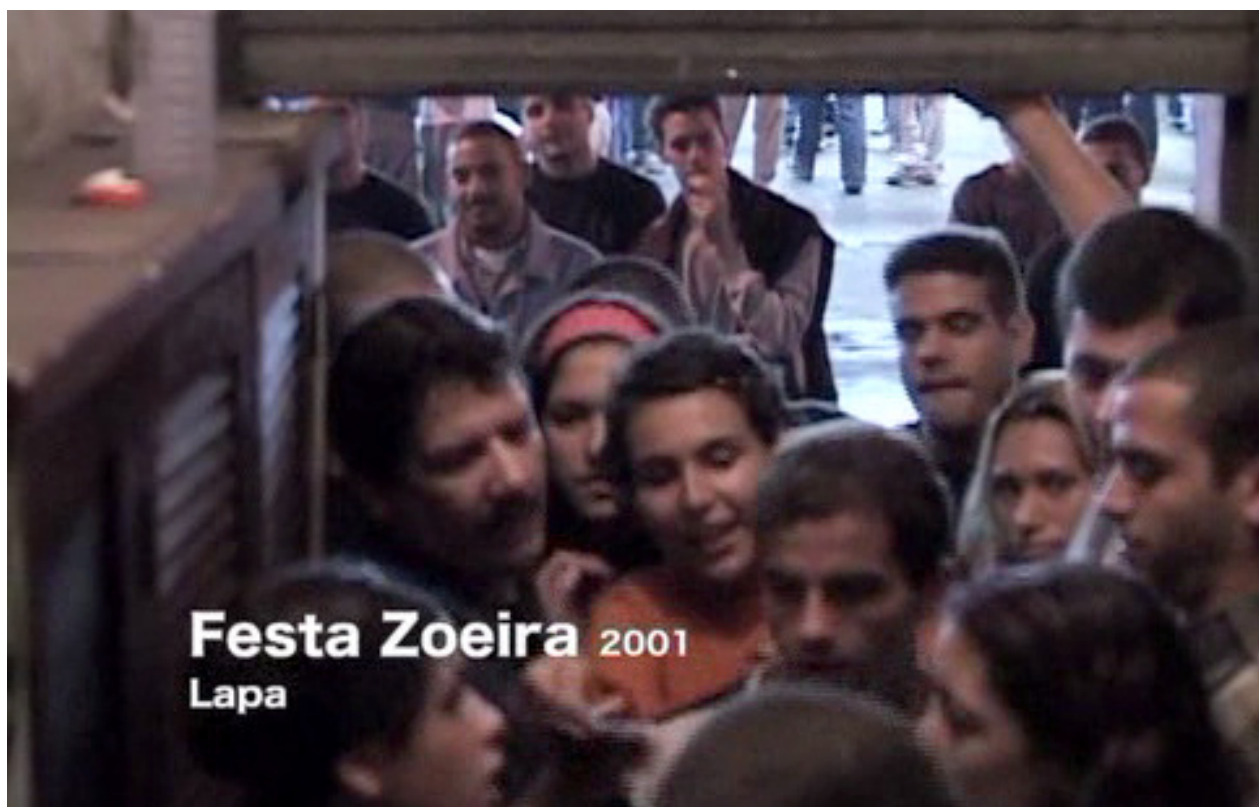

A festa Zoeira Hip-Hop foi um dos pontapés iniciais para a cena hip-hop no Rio de Janeiro. Idealizada pela produtora Elza Cohen, a festa teve seu inicio no final de 1997 na Sinuca da Lapa, e a Zoeira ajudou a consagrar uma nova cena de $M C^{\prime}$ 's, $D J$ 's, grafiteiros e $b$-boys, levando à Lapa uma nova geração de frequentadores de eventos desse gênero. A festa rolou do final de 1997 até 2003 como um importante ponto de encontro das gerações, um local de troca de ideias, batidas e rimas. Na época, acabou porque o espaço virou Igreja Universal. Um dos principais momentos do Hip Hop do Rio foi promovido pela Zoeira. Na coletânea publicada na Revista Trip, em que divulgou para o Brasil todo o hip hop carioca e também em alguns lugares no mundo. Foi nessa época que saíram matérias e entrevistas na revista The Source (USA), DUNE (Japão), Canamo (Espanha), HipHop360.com (NY), Tribeca (Paris), especiais na MTV, Multishow, TV Cultura Rio, destaque nos principias jornais, revistas do Brasil e documentários. A festa voltou a acontecer em 2005 no Rio de Janeiro, trazendo de volta uma noite de qualidade à cidade, onde só aconteciam, em sua maioria, festas em boates com sons da moda e com publico não segmentado. A volta da Zoeira trouxe novamente um rap refinado nos toca-discos e as famosas e memoráveis rodas de Freestyle que rolavam só lá. Esse ano a Zoeira começou a ter edições mensais na cidade da São Paulo, tornando-se uma das melhores festas paulistanas. Sempre com casa cheia e promovendo shows e lançamentos de discos, como do Slim Rimografia, Contra-Fluxo e lançamentos da coletânea Smoking Hip-Hop. Foi a festa responsável pelo encerramento do documentário "BRASILINTIME", que teve a presença e participação de todos os DJs envolvidos no filme, tais como: Erick Coleman, J-Rocc, Madlib, Primo, Nuts, entre outros, fazendo um dos eventos mais bem sucedidos do ano. Além dos DJs residentes Zinco (em SP e RJ) e Tamenpi (RJ) e Mc Marechal, a Zoeira sempre conta com um line-up de convidados especiais a cada evento, entre, DJs, MCs, músicos, artistas visuais urbanos, break, etc. 
Portanto, ao abordar vivências distintas de músicos que possuem a Lapa como ponto de encontro comum, o documentário explora não só o potencial da região como também o exercício de troca que há entre o movimento hip-hop e aqueles que se propõem a utilizá-lo como instrumento para a organização de um grupo cujo foco é a construção de uma identidade cultural pela música. Aqui, L.A.P.A não fica apenas na abordagem sobre um bairro ou um movimento, conforme salienta Oliveira (2009), o documentário passa a frisar naquilo que há de valioso ali é esse contato com o nascimento de artistas vigorosos em toda sua ânsia juvenil, e como a natureza do rap é tão mais reveladora nesse sentido, uma vez que não só assistimos uma expressão se repetir em cena, mas sim o próprio nascimento dela, da poesia, ali de onde menos se espera que ela surja.

No choque das espontaneidades, não há imagem fabricada pelo filme que resista a esse pulso criativo no interior da cena, igualmente fabricado, mas muito mais disponível a dialogar com tempos, espaços e histórias que se imponham com força maior que a sua. Logo, L.A.P.A é um filme sobre a Lapa, o movimento hip-hop e a mescla desses dois elementos, que configuram o bairro carioca como um elemento cultural único em que a música mantém o fluxo de ambos.

\section{Referências bibliográficas}

ACADEMIA BRASILEIRA DE CINEMA. L.A.P.A. Disponível em: <http://www. academiabrasileiradecinema.com.br>. Acesso em 13 Jun. 2013.

BOURDIEU, Pierre. O mercado de bens simbólicos. In: A economia das trocas simbólicas. São Paulo: Perspectiva, 2001.

FRANCE, Claudine. Do filme antropológico à antropologia filmica. Campinas: Editora da Unicamp, 2000.

HERSCHMANN, Micael. Lapa, cidade da música: desafios e perspectivas para o crescimento do Rio de Janeiro e da indústria da música independente nacional. Rio de Janeiro: Mauad X, 2007.

LUSTOSA, Isabel. Lapa do desterro e do desvario: uma antologia. Rio de Janeiro: Casa da Palavra, 2001.

MIOTELLO, V. Ideologia. In: BRAIT, B. (Org.). Bakhtin: conceitos-chave. 4. ed. São Paulo: Contexto, 2007.

OLIVEIRA, Lúcia Maciel Barbosa de Oliveira. Identidade cultural: conceito. Disponível em: <http://escola.mpu.mp.br/>. Acesso em 03 Jul. 2013.

OLIVEIRA, Rodrigo de. L.A.P.A., de Cavi Borges e Emílio Domingos (Brasil, 2007). Revista Cinética, abr. 2009. Disponível em: <http://www.revistacinetica.com.br/ lapa.html>. Acesso em 03 Jul. 2013.

SOUZA, Gustavo. Culturas urbanas periféricas no documentário brasileiro: Funk, Hip- Hop e Samba. Disponível em: <http://www.cult.ufba.br/enecul2006/ gustavo_souza.pdf $>$. Acesso em 13 Jun. 2013.

THOMPSON, Paul. A voz do passado: história oral. Rio de Janeiro: Paz e Terra, 1992.

XAVIER, Ismail. O Cinema Brasileiro Moderno. São Paulo: Paz e Terra. 2001.

ZENI, Bruno. O nego drama do rap: entre a lei do cão e a lei da selva. Disponível em: <http://www.scielo.br/pdf/ea/v18n50/a20v1850.pdf>. Acesso em 03 Jul. 2013. 


\section{Filmografia}

L.A.P.A. Direção: Cavi Borges e Emílio Domingos. Produção: Cavi Borges e Gustavo Pizzi. Roteiro: Emilio Domingos e Cavi Borges. Rio de Janeiro: [s.n.], 2007. 73 $\min$.

RIO, Uma Cidade de Leitores. Programa n.36 - HIP HOP. 27 de Maio de 2010. Disponível em: <https://www.youtube.com/watch?v=jl--zMMrA-c >. Acesso em: 20 Mai. 2013. 